\title{
Invasion of Artificial Vascular Graft into Duodenal Bulb after Living Donor Liver Transplantation
}

\author{
Yu-Ju Hung1, Kuo-Hua Lin', Chen-Te Chou', Chih-Jan Ko', Ping-Yi Lin ${ }^{3}$, Chia-En Hsieh1, \\ Hsu-Heng Yen ${ }^{4}$, Yao-Li Chen ${ }^{*}$ \\ ${ }^{1}$ Department of Surgery, Changhua Christian Hospital, Changhua, Chinese Taipei \\ ${ }^{2}$ Department of Medical Imaging, Changhua Christian Hospital, Changhua, Chinese Taipei \\ ${ }^{3}$ Transplant Medicine \& Surgery Research Centre, Changhua Christian Hospital, Changhua, Chinese Taipei \\ ${ }^{4}$ Department of Gastroenterology, Changhua Christian Hospital, Changhua, Chinese Taipei \\ Email: 31560@cch.org.tw
}

Received 18 January 2015; accepted 12 February 2015; published 15 February 2015

Copyright (C) 2015 by authors and Scientific Research Publishing Inc.

This work is licensed under the Creative Commons Attribution International License (CC BY).

http://creativecommons.org/licenses/by/4.0/

(c) (i) Open Access

\begin{abstract}
Artificial vessel grafts are used for outflow reconstruction in living donor liver transplantation (LDLT). We report a very rare case of invasion of an artificial vascular graft into the duodenal bulb after LDLT. A 54-year-old man underwent LDLT in August 2012. A right hemiliver without a middle hepatic vein was used as a graft. The outflow of segment $V$ was created by anatomizing an artificial graft to the inferior vena cava. During outpatient follow-up, the patient complained of acid regurgitation but did not experience abdominal pain. Panendoscopy was arranged and it revealed that the artificial graft had invaded the duodenal bulb. Operation was performed to remove the graft and the patient discharged after fourteen days of hospital stay. Invasion of artificial vascular grafts to adjacent organs is rare, but happens in living donor liver transplantation. It may be caused by inappropriate vessel graft length and adhesion between the graft and adjacent organs.
\end{abstract}

\section{Keywords}

Living Donorliver Transplantation, Artificialgraft

\section{Introduction}

Living donor liver transplantation (LDLT) is a treatment option for patients with end stage liver disease or

*Corresponding author.

How to cite this paper: Hung, Y.-J., Lin, K.-H., Chou, C.-T., Ko, C.-J., Lin, P.-Y., Hsieh, C.-E., Yen, H.-H. and Chen, Y.-L. (2015) Invasion of Artificial Vascular Graft into Duodenal Bulb after Living Donor Liver Transplantation. Surgical Science, 6, 71-74. http://dx.doi.org/10.4236/ss.2015.62012 
hepatocellular carcinoma when cadaveric donor organs are not available. One of the major technical challenges of LDLT is the outflow reconstruction of the right liver graft. Outflow obstruction may cause liver congestion and lead to graft failure [1] [2].

There are three types of venoplasty for outflow reconstruction in LDLT, which includs cryopreserved vascular grafts, autologous vein grafts and artificial vascular grafts. Among them, artificial vascular grafts are useful interpositional materials and are most frequently used [3]. These grafts are used in our institution for anterior section drainage because they are easier to prepare than cryopreserved vessels and autologous grafts. We report a very rare case of invasion of an artificial vascular graft (expanded polytetrafluoroethylene; ePTFE) into the duodenal bulb after LDLT.

\section{Case Presentation}

A 54-year-old man with hepatitis B and C as well as alcoholic liver cirrhosis underwent LDLT in August 2012. A right hemiliver without a middle hepatic vein was used as a graft. The segment $\mathrm{V}$ outflow was created by anatomizing an ePTFE artificial graft to the inferior vena cava (Figure 1(A)). Approximately one week after surgery, the patient presented with obstructive jaundice due to stricture at the site of the bile duct. Endoscopic retrograde biliary drainage was performed on the ninth postoperative day. Jaundice resolved shortly after the procedure and the patient was discharged two weeks after the operation.

During outpatient follow-up, the patient complained of acid regurgitation but did not experience abdominal pain. Routine panendoscopy to remove the biliary drainage stent about six months later revealed that the artificial graft had invaded the duodenal bulb (Figure 1(B)). Computed tomography (Figure 1(C)) revealed air in the graft but no other adjacent organ injury was noted. A duodenostomy was performed to excise the graft, which had migrated into the duodenal bulb (Figure 1(D)). The graft was no longer patent and was filled with debris. Low grade fever was noted post operatively and empiric antibiotics were administered for 2 weeks. Cultures of

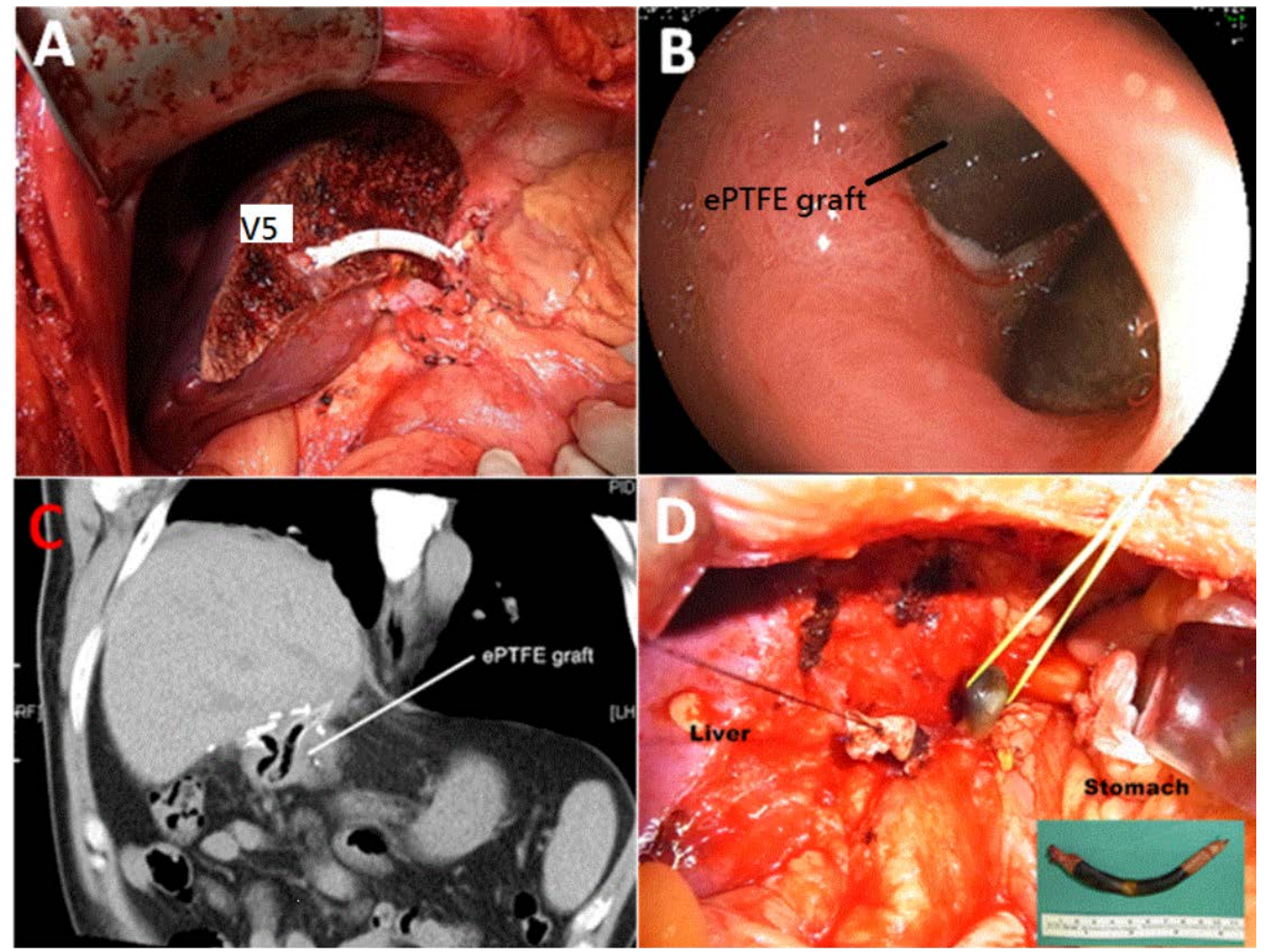

Figure 1. (A): V5 was reconstructed by anastomosing an ePTFE graft to the inferior vena cava. (B): Endoscopic examination revealed invasion of the artificial graft into the duodenal bulb. (C) and (D): CT images and peri-operative surgical photograph revealed a non-patent ePTFE graft embedded in the duodenal bulb. 
the artificial graft grew Prevotella spp. and Candida tropicalis. Blood culture was negative for bacterial growth. The patient was discharged on regular diet 14 days after surgery.

\section{Discussion}

Artificial vascular grafts are most frequently used for venous drainage of the liver graft in living donor liver transplantation because they are easy to prepare and may reduce the operation time, furthermore, the surgical results are comparable with autologous and cryopreserved grafts [4] [5]. But complication related to ePTFE grafts after LDLT was not well reviewed in the literature. Honda et al. [6] reported a rare case of migration of an artificial graft into the small intestine 6 months after coronary artery bypass surgery and mesenteric artery bypass surgery. Kim et al. [7] once reported that adjacent-organ injuries by ePTFE graft after LDLT were rare but present, the incidence was about $1.96 \%$.

Adhesion of artificial vascular grafts to adjacent organs, such as the stomach, duodenum or extrahepatic bile duct, can result in vascular graft migration. It may be caused by long vessel graft length and adhesion between the grafts and adjacent organs. The length of the ePTFE graft was too long in this case which leaded to the invasion of the duodenum by the ePTFE graft. But there is no precise formula for vessel length calculation in LDLT. An omental flap was once suggested for prevention of adhesion [7], but the procedure was time-consuming. In our hospital, we apply surgical tissue adhesives (fibrin sealant; Tissucol Duo Quick, 2 ml/set) over the liver raw surface and vessel grafts for adhesion prevention in every recipient. In addition to adhesion prevention, we found out that the surgical tissue adhesives can keep vessels from twisting, so they can maintain good blood flow.

\section{Discussion}

Artificial vascular grafts are most frequently used for venous drainage of the liver graft in living donor liver transplantation because they are easy to prepare and may reduce the operation time, furthermore, the surgical results are comparable with autologous and cryopreserved grafts [4] [5]. But complication related to ePTFE grafts after LDLT was not well reviewed in the literature. Honda et al. [6] reported a rare case of migration of an artificial graft into the small intestine 6 months after coronary artery bypass surgery and mesenteric artery bypass surgery. Kim et al. [7] once reported that adjacent-organ injuries by ePTFE graft after LDLT were rare but present, the incidence was about $1.96 \%$.

Adhesion of artificial vascular grafts to adjacent organs, such as the stomach, duodenum or extrahepatic bile duct, can result in vascular graft migration. It may be caused by long vessel graft length and adhesion between the grafts and adjacent organs. The length of the ePTFE graft was too long in this case which leaded to the invasion of the duodenum by the ePTFE graft. But there is no precise formula for vessel length calculation in LDLT. An omental flap was once suggested for prevention of adhesion [7], but the procedure was time-consuming. In our hospital, we apply surgical tissue adhesives (fibrin sealant; Tissucol Duo Quick, 2 ml/set) over the liver raw surface and vessel grafts for adhesion prevention in every recipient. In addition to adhesion prevention, we found out that the surgical tissue adhesives can keep vessels from twisting, so they can maintain good blood flow.

\section{Conclusion}

Invasion of artificial vascular grafts to adjacent organs is rare, but happens in living donor liver transplantation. It may be caused by inappropriate vessel graft length and adhesion between the graft and adjacent organs.

\section{References}

[1] Lo, C.-M., Fan, S.-T., Liu, C.-L. and Wong, J. (2003) Hepatic Venoplasty in Living-Donor Liver Transplantation Using Right Lobe Graft with Middle Hepatic Vein. Transplantation, 75, 358-360. http://dx.doi.org/10.1097/01.TP.0000046527.19422.3E

[2] Lee, S.G., Park, K.M., Hwang, S., et al. (2001) Congestion of Right Liver Graft in Living Donor Liver Transplantation. Transplantation, 71, 812-814. http://dx.doi.org/10.1097/00007890-200103270-00021

[3] Wang, C.C., Lopez-Valdes, S., Lin, T.-L., et al. (2014) Outcomes of Long Storage Times for Cryopreserved Vascular Grafts in Outflow Reconstruction in Living Donor Liver Transplantation. Liver Transplantation, 20, 173-181. http://dx.doi.org/10.1002/lt.23785 
[4] Kim, B.-W., Wang, H.-J., Lee, B.M., et al. (2007) Middle Hepatic Vein Reconstruction of Right Liver Graft Using the Glutaraldehyde-Treated Acellular Bovine Pericardium. Surgery, 141, 832-834. http://dx.doi.org/10.1016/j.surg.2007.01.034

[5] Yi, N.-J., Suh, K.-S., Lee, H.W., et al. (2007) An Artificial Vascular Graft Is a Useful Interpositional Material for Drainage of the Right Anterior Section in Living Donor Liver Transplantation. Liver Transplantation, 13, 1159-1167. http://dx.doi.org/10.1002/lt.21213

[6] Honda, K., Okamura, Y., Nishimura, Y. and Uchita, S. (2013) Migration of the Ringed ePTFE Graft into the Small Intestine. Journal of Vascular Surgery, 57, 525. http://dx.doi.org/10.1016/j.jvs.2011.11.051

[7] Kim, M.J., Kim, H.B., Han, J.K., et al. (2011) Injuries of Adjacent Organs by the Expanded Polytetrafluoroethylene Grafts in the Venoplasty of Middle Hepatic Veins in Living-Donor Liver Transplantation: Computed Tomographic Findings and Possible Risk Factors. Journal of Computer Assisted Tomography, 35, 544-548. http://dx.doi.org/10.1097/RCT.0b013e318227a68a 
Scientific Research Publishing (SCIRP) is one of the largest Open Access journal publishers. It is currently publishing more than 200 open access, online, peer-reviewed journals covering a wide range of academic disciplines. SCIRP serves the worldwide academic communities and contributes to the progress and application of science with its publication.

Other selected journals from SCIRP are listed as below. Submit your manuscript to us via either submit@scirp.org or Online Submission Portal.
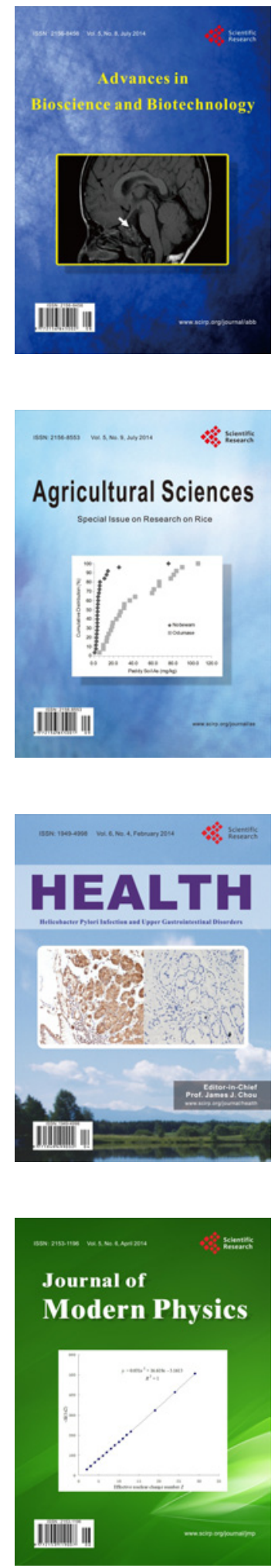
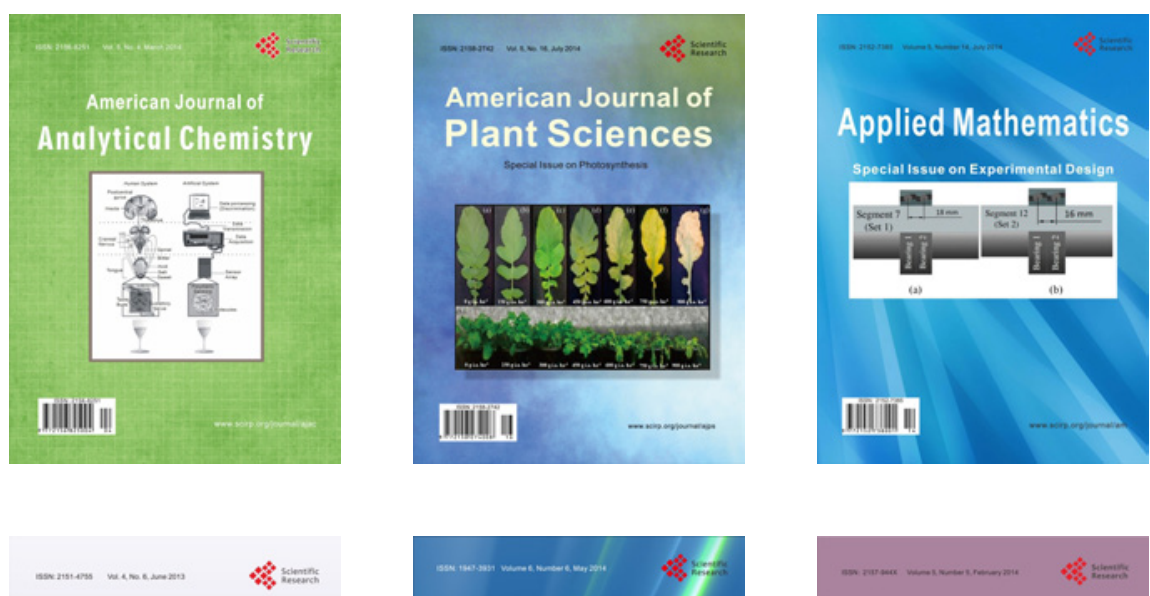

Creative Education
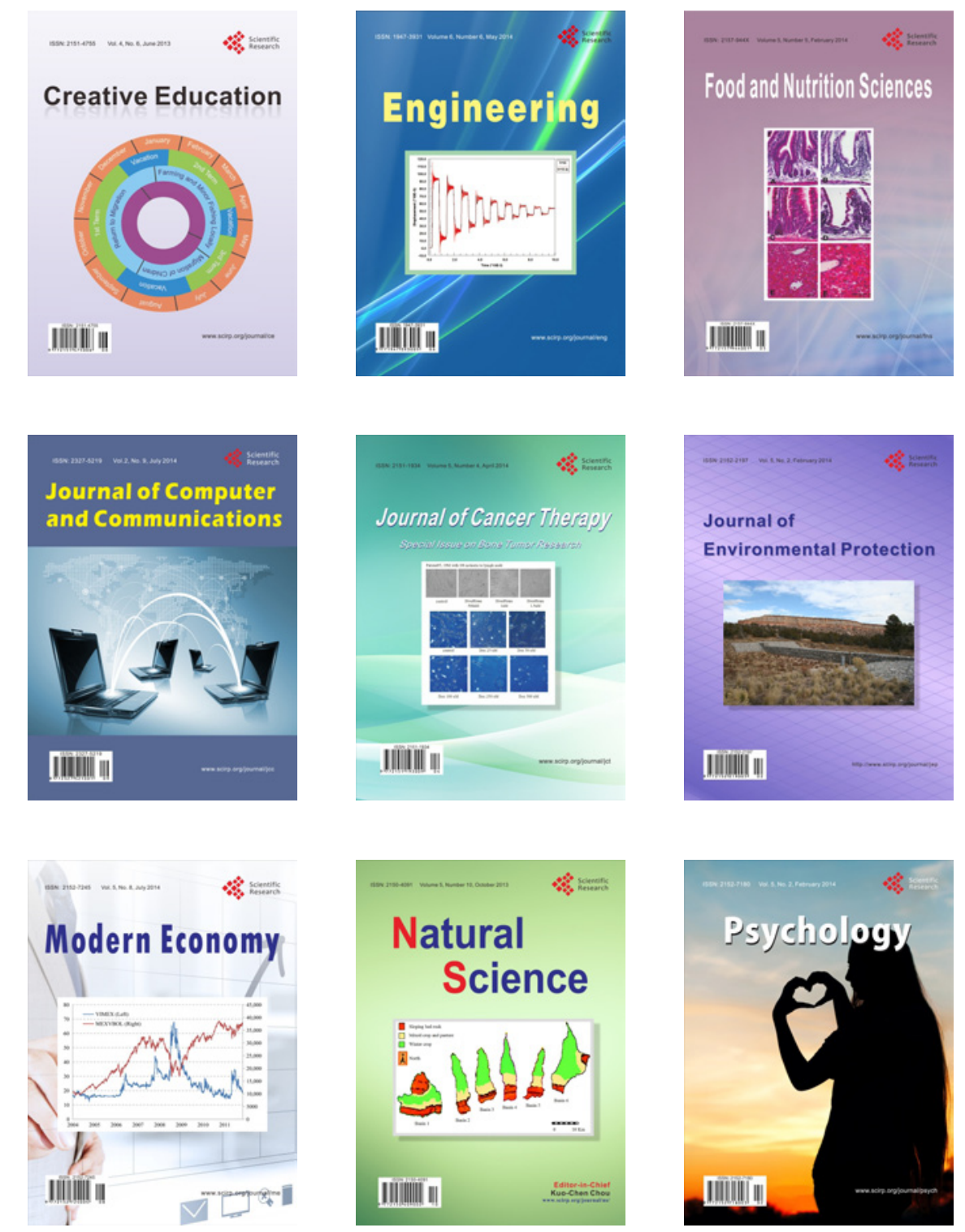